\title{
Inflammatory cytokines in CSF in bacterial meningitis: association with altered blood flow velocities in basal cerebral arteries
}

\author{
Klaus Fassbender, Stefan Ries, Ulf Schminke, Susanne Schneider, Michael Hennerici
}

\begin{abstract}
Objective-To investigate the association between release of humoral inflammatory mediators in CSF and blood and alterations of cerebral blood flow in patients with bacterial meningitis.

Methods-Immunomodulatory (interleukin-1 $\beta$ (IL-1 $\beta$ ), interleukin-6 (IL-6), and tumour necrosis factor- $\alpha$ (TNF $\alpha$ )) and vasoactive (thromboxane $A$, prostacyclin, endothelin-1) molecules of probable or confirmed leucocyte origin were determined in CSF and venous blood from 20 patients with bacterial meningitis, and matched control subjects. Their concentrations were related to the presence of increased blood flow velocities in the middle cerebral arteries, as recorded by transcranial Doppler sonography.

Results-Concentrations of proinflammatory cytokines and prostacyclin and leucocyte counts were significantly increased in meningitis, but concentrations of the vasoconstrictors thromboxane and endothelin-1 were not. Patients with high blood flow velocities $(>140 \mathrm{~cm} / \mathrm{s})$ had significantly increased concentrations of IL-1 $\beta$ and IL-6 and raised cell counts in CSF.

Conclusion-The increases of key mediators of inflammation and immunoactivation and of leucocyte count in the CSF of patients with high cerebral blood flow velocities suggest a role of excessive compartmentalised host defence in pathogenesis of disorders of cerebral blood flow in bacterial meningitis.
\end{abstract}

(F Neurol Neurosurg Psychiatry 1996;61:57-61)

Keywords: cytokines; meningitis; cerebral blood flow

Department of Neurology, University of Heidelberg, Klinikum Mannheim, Germany

K Fassbender

$S$ Ries

U Schminke

S Schneider

M Hennerici

Correspondence to:

Dr K Fassbender,

Department of Neurology,

Klinikum Mannheim,

University of Heidelbers

Theodor-Kutzer-Ufer, 68135

Mannheim, Germany.

Received 9 August 1995 and in final revised form 5 March 1996

Accepted 7 March 1996

Cerebrovascular disorders have been documented as one of the most common intracranial complications in adults with bacterial meningitis. ${ }^{1}$ Narrowing of basal cerebral arteries has been shown by angiography at sites where they are bathed within the subarachnoidal exudate in the cisterns and subarachnoidal space, and has been discussed as a in this disease. ${ }^{2-4}$ An increased cerebral blood flow velocity (CBFV) in the basal cerebral arteries has been shown in bacterial meningitis by transcranial Doppler sonography. ${ }^{5-7}$ An inverse relation between vessel diameter on
Doppler sonography has been found, ${ }^{8}$ and there is considerable evidence that these alterations reflect changes in calibre of the insonated vessels as a result of transient or persistent narrowing of cerebral vessels. ${ }^{5-7}$ The non-invasive character of this method facilitates studies of disorders of cerebral blood flow in patients with meningitis.

Most humoral factors considered to play a part in the pathogenesis of vasospasms in subarachnoidal haemorrhage-for example, erythrocyte or platetet derived products-are absent in bacterial meningitis. The hallmark of bacterial meningitis is a massive leucocyte infiltration into the perivascular spaces and the CSF. ${ }^{9}$ These cells act through synthesis of proinflammatory cytokines (interleukin-1 $\beta$ (IL-1 $\beta$ ), interleukin-6 (IL-6), and tumour necrosis factor- $\alpha$ (TNF $\alpha)$ ), which orchestrate the local and systemic aspects of host response to infection and tissue damage. ${ }^{1011}$ Huge amounts of these cytokines have recently been detected in $\mathrm{CSF}$ in bacterial meningitis. ${ }^{12}$ Arachidonic acid metabolites are also important mediators of inflammation. ${ }^{13}$ An imbalance between the potent vasoconstrictor thromboxane $\mathrm{A}_{2}$ and the vasodilator prostacyclin has been implicated in the pathogenesis of cerebral vasospasms after subarachnoidal haemorrhage. ${ }^{14}$ Their synthesis also belongs to the repertoire of activated leucocytes. ${ }^{15}$ Endothelin-1 induces extremely sustained vasoconstriction, and is discussed as a causal factor in vasospasms secondary to subarachnoid haemorrhage. ${ }^{16}{ }^{17}$ Its synthesis by leucocytes after bacterial lipopolysaccharide stimulation, ${ }^{18}$ the induction of synthesis by polymorphonuclear leucocytes ${ }^{19}$ and cytokines, ${ }^{20} 21$ and the presence of a consensus sequence for acute phase elements in its gene ${ }^{22}$ prompted us to include investigation of endothelin-1 in this study.

By contrast with the many studies on subpathomechanism of cerebral infarctions seen angiography and CBFV on transcranial have, to our know patients with alterations of cerebral blood flow in meningitis. The aim of this study was to characterise the release of immunocompetent and vasoactive leucocyte products within the CSF in relation to alterations of cerebral blood flow in patients with bacterial meningitis.

\section{Patients and methods}

PATIENTS

Twenty patients (seven women and 13 men) aged between 18 and 85 (median 45) with 
pyogenic meningitis, admitted within 48 hours after onset of first symptoms, were included in this study. Diagnosis was based on evidence from cultures of a predominant microorganism from a CSF sample and/or pleocytosis of $>1000$ cells $/ \mathrm{mm}^{3},>60 \%$ polymorphonuclear CSF leucocytes, pronounced increase in protein concentration, clinical signs and symptoms of bacterial meningitis (fever, nuchal rigidity, headache, photophobia), and evidence for a systemic inflammatory response (increased white cell count and concentrations of $\mathrm{C}$ reactive protein). The causative organisms were Streptococcus pneumoniae $(\mathrm{n}=5)$, Staphylococcus aureus ( $\mathrm{n}=4)$, Escherichia coli $(\mathrm{n}=2), \quad$ Neisseria meningitidis $(\mathrm{n}=2)$, Haemophilus influenzae $\quad(\mathrm{n}=2)$, Mycobacterium tuberculosis $(\mathrm{n}=1)$, and Listeria monocytogenes $(\mathrm{n}=1)$. In three patients, no aetiological microorganism was isolated. These patients had received antibiotics before admission to hospital. Moreover, they showed a rapid response to antibiotic treatment. In 12 patients, the infection was community acquired, and in eight nosocomial. Other diseases known to be associated with alterations of blood flow in basal arteries (for example, subarachnoid haemorrhage) were excluded by clinical and laboratory examinations and by cranial CT.

Samples of of CSF and serum from 20 subjects matched in age and sex (10 women and 10 men) aged between 26 and 71 (median 43) were used for controls. These were examined for exclusion of possible inflammatory disease, but turned out to have no neurological disease after extensive clinical examination and laboratory tests, including standard blood and CSF analyses.

TRANSCRANIAL DOPPLER SONOGRAPHY

The CBFV was recorded with transcranial Doppler ultrasound in parallel with collection of blood and CSF samples. Transcranial Doppler examinations were performed with a DWL Multidop X TCD device (DWL Sipplingen, Germany). Maximum systolic CBFV values were measured transtemporally in the proximal segment of the middle cerebral arteries. Reference values were derived from our transcranial Doppler readings in normal volunteers $^{23}$ (table 1). Patients with systolic blood flow velocities in one or both middle cerebral arteries exceeding $140 \mathrm{~cm} / \mathrm{s}$ (exceeding normal values by $3 \mathrm{SD}^{23}$ ) were considered to have raised $\mathrm{CBFV}$. This cut off value had been shown to be useful in earlier studies. ${ }^{24}$

SAMPLE HANDLING AND ROUTINE ANALYSES Paired samples of blood and CSF from patients with meningitis were obtained at admission (within 48 hours after the onset of symptoms). Routine CSF analysis included cell count, cytology, albumin, and the albumin quotient ([CSF albumin] $\times 10^{3} /[$ serum albumin]). For analysis, the collected CSF and blood samples were centrifuged at $3000 \mathrm{rpm}$ for five minutes and the supernatant was stored at $-80^{\circ} \mathrm{C}$ until used.
PROINFLAMMATORY CYTOKINES

Concentrations of IL- $1 \beta$, IL-6, and TNF $\alpha$ were determined in CSF and serum with quantitative "sandwich" enzyme immunoassays ( $R$ and D Systems, Minneapolis, $M N$, USA), with antibodies specific for these cytokines coated on to microtitre plates and enzyme linked polyclonal specific antibodies, added after washing. The lower limits of detection for IL- $1 \beta$, IL- 6 , and TNF $\alpha$ were $0.3 \mathrm{pg} / \mathrm{ml}, 0.7 \mathrm{pg} / \mathrm{ml}$, and $4.4 \mathrm{pg} / \mathrm{ml}$, respectively.

\section{EXTRACTION AND QUANTIFICATION OF} EICOSANOIDS

Eicosanoids were extracted from CSF and plasma by addition of chloric acid and ethyl acetate. The organic phase was evaporated under $\mathrm{N}_{2}$ and reconstituted with radioimmunoassay buffer. The stable metabolites thromboxane $\mathrm{B}_{2}$ and 6-keto-prostaglandin $\mathrm{F}_{1 \alpha}$ were used to estimate the amounts of thromboxane $\mathrm{A}_{2}$ and prostacyclin respectively. Thromboxane $B_{2}$ and 6-keto-prostaglandin $F_{1 \alpha}$ were both determined by radioimmunoassays (PerSeptive Diagnostics, Cambridge, MA). Briefly, these are based on competition of analyte in the samples with [ $\left.{ }^{125} \mathrm{I}\right]$ labelled analyte for a limited number of sites on a specific rabbit antianalyte antibody. Antibody bound analyte is separated from unbound analyte with goat antirabbit IgG through centrifugation, and the antibody bound labelled analyte is quantified in a gamma counter. The sensitivity of determination of thromboxane $\mathrm{B}_{2}$ and $\mathrm{PGF}_{1 \alpha}$ was $<6.0 \mathrm{pg} / \mathrm{ml}$ and $<3.3 \mathrm{pg} / \mathrm{ml}$ respectively.

EXTRACTION AND ASSAY OF ENDOTHELIN-1

Endothelin-1 was extracted from acidified samples on $\mathrm{C} 18$ columns by the addition of acetic acid and evaporated under nitrogen gas. After reconstitution in an assay buffer, the extracted endothelin was measured in a radioimmunoassay (Nichols Institute Diagnostics, San Juan Capistrano, CA). Radiolabelled endothelin-1 competes with endothelin in the test samples for a limited number of rabbit antianalyte sites. Antibody bound endothelin is separated from free endothelin using antirabbit IgG antibody coated cellulose in suspension as the solid phase. The unbound endothelin is decanted after centrifugation and the endothelin is measured in a gamma counter. The sensitivity of the assay was $2 \mathrm{pg} / \mathrm{ml}$.

\section{STATISTICS}

Because considerable amounts of prostaglandins and endothelin are present in normal serum, a "protein index"-by analogy with the IgG index - was used to correct for passage in CSF through a disrupted blood brain barrier. Results are expressed as mean (SE). Values were log transformed before statistical analysis, because their frequency distributions were asymmetric. For statistical analysis, the Student's $t$ test for unpaired data with a Bonferroni correction was employed to assess the significance of the difference between 
Table 1 Mean (SE) systolic blood flow velocities in bacterial meningitis

\begin{tabular}{|c|c|c|c|c|}
\hline & & \multicolumn{3}{|l|}{ Cerebral artery } \\
\hline & & Middle & Anterior & Posterior \\
\hline Meningitis & $\begin{array}{l}\text { Left } \\
\text { Right }\end{array}$ & $\begin{array}{l}156.4(14.5) \\
161.0(12.9)\end{array}$ & $\begin{array}{l}104.9(10.5) \\
135.3(8.5)\end{array}$ & $\begin{array}{l}71 \cdot 2(7 \cdot 5) \\
67 \cdot 3(6 \cdot 2)\end{array}$ \\
\hline \multicolumn{2}{|c|}{ Reference values ${ }^{\star}$} & $94.5(1.9)$ & $76 \cdot 4(2 \cdot 4)$ & $53.2(1.6)$ \\
\hline
\end{tabular}

^Reference values were derived from earlier transcranial Doppler readings in normal volunteers. ${ }^{23}$

groups. Thus values of $P<0 \cdot 05 / 10$ (10 being the number of the different mediators investigated in CSF) were required for differences to be considered significant. For the comparison of the differences between patients with high and low CBFV, values of $P<0.05 / 5$ (five being the number of the different mediators tested) were required to be considered significant.

\section{Results}

CEREBRAL BLOOD FLOW VELOCITY

Table 1 presents values of CBFV in patients with meningitis, as well as reference values. Eleven of 20 patients with bacterial meningitis had high CBFVs. A considerable asymmetry was noted. Only seven of 11 of the patients in the subpopulation with high CBFVs showed simultaneously increased values in both middle cerebral arteries.

CELL COUNTS AND ALBUMIN QUOTIENT

As expected, cell counts were significantly increased in the CSF of patients with meningitis (table 2). Cell counts were significantly increased in patients with high CBFVs (figure). Albumin quotients were massively increased in bacterial meningitis (mean 30.70 (SE 7·27)).

\section{PROINFLAMMATORY CYTOKINES}

Concentrations of the cytokines IL- $1 \beta, \mathrm{TNF} \alpha$, and IL- 6 were significantly increased in CSF of patients with meningitis (table 2). Concentrations of IL- $1 \beta$ and IL- 6 were significantly raised in patients exhibiting increased CBFVs (figure), whereas the concentrations of TNF $\alpha$ tended to be increased in this subpopulation, but without reaching statistical significance.

THROMBOXANE AND PROSTACYCLIN

Concentrations of the stable metabolites of prostacyclin (6-keto prostaglandin $F_{1 \alpha}$ ) were

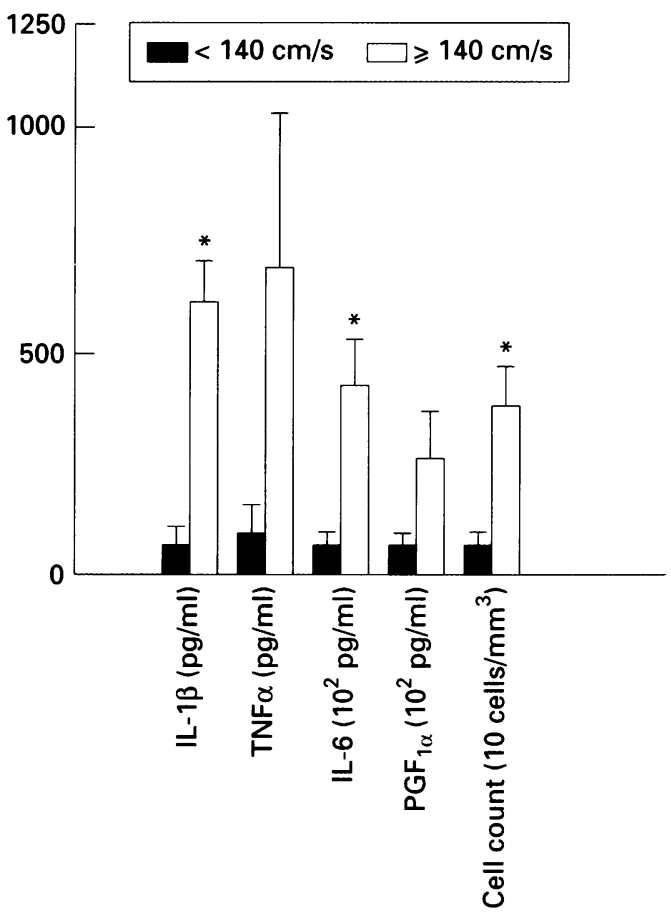

Mean concentrations (SE) of IL-1 $\beta, T N F \alpha, I L-6$, prostaglandin $F_{\text {to }}$ and cell counts in patients with meningitis exhibiting CBFVs of $<$ or $>140 \mathrm{~cm} / \mathrm{s}$. ${ }^{*} P<0.05$ (after Bonferroni correction).

significantly increased in the CSF of patients with bacterial meningitis. However, concentrations of this prostaglandin did not significantly differ in the study groups with higher or lower CBFV (figure). Although the highly variable CSF concentrations of the stable metabolite of thromboxane $A_{2}$ (thromboxane $B_{2}$ ) tended to be raised in meningitis, a significant difference could not be found. The indices of both eicosanoids studied were not significantly increased.

\section{ENDOTHELIN-1}

Concentrations of this vasoconstrictor were highly variable in patients with meningitis (table 2). Four patients with bacterial meningitis exhibited high CSF concentrations (13.58, 14.08, 18.77, and $19.52 \mathrm{pg} / \mathrm{ml})$. However, when the study populations with and without meningitis were compared, neither CSF concentrations nor the corresponding index differed significantly (table 2).

Table 2 Mean concentrations (SE) of immunomodulatory and vasoactive mediators in patients with meningitis and controls subjects

\begin{tabular}{|c|c|c|c|c|c|c|}
\hline \multirow[b]{2}{*}{ Variable } & \multicolumn{3}{|c|}{ Control subjects } & \multicolumn{3}{|c|}{ Patients with meningitis } \\
\hline & CSF & Serum & Indext & $C S F$ & Serum & Indext \\
\hline $\begin{array}{l}\text { Cells } / \mathrm{mm}^{3} \\
\text { IL-1 } \beta(\mathrm{pg} / \mathrm{ml}) \\
\text { IL-6 } 6 \text { pg/ml }) \\
\text { TNF } \alpha(\mathrm{pg} / \mathrm{ml}) \\
\text { TbXB }(\mathrm{pg} / \mathrm{ml}) \\
\text { PGF } \alpha(\mathrm{ng} / \mathrm{ml}) \\
\text { ET-1 }(\mathrm{pg} / \mathrm{ml})\end{array}$ & $\begin{array}{r}0.9(0.3) \\
0.0(0.0) \\
6 \cdot 1(2.5) \\
0.2(0.1) \\
15.8(6.4) \\
2.4(1 \cdot 1) \\
1.8(1.0)\end{array}$ & $\begin{array}{c}- \\
0 \cdot 0(0 \cdot 0) \\
1 \cdot 3(0 \cdot 2) \\
2 \cdot 1(0 \cdot 4) \\
1201 \cdot 0(378 \cdot 1) \\
8 \cdot 2(2 \cdot 5) \\
3 \cdot 4(0 \cdot 4)\end{array}$ & $\begin{array}{l}\bar{Z} \\
= \\
\overline{1} \cdot 2(5 \cdot 8) \\
58 \cdot 6(16 \cdot 0) \\
80 \cdot 7(21 \cdot 1)\end{array}$ & $\begin{array}{c}2713.5(613.5)^{\star} \\
417.2(91.9)^{\star} \\
30281 \cdot 1(8070.3)^{\star} \\
474.9(220.7)^{\star} \\
326.3(205 \cdot 4) \\
20.6(7.3)^{\star} \\
5.9(1.9)^{\star}\end{array}$ & $\begin{array}{c}- \\
4 \cdot 8(1 \cdot 8) \\
248 \cdot 4(99 \cdot 9) \\
11 \cdot 6(8 \cdot 8) \\
920 \cdot 7(625 \cdot 5) \\
27 \cdot 4(4 \cdot 2) \\
4 \cdot 8(1 \cdot 1)\end{array}$ & $\begin{array}{l}\bar{Z} \\
\bar{Z} \\
\overline{18} \cdot 9(9 \cdot 8) \\
51 \cdot 2(18 \cdot 0) \\
58 \cdot 7(15 \cdot 7)\end{array}$ \\
\hline
\end{tabular}

$\star \mathrm{P}<0.05$ (after Bonferroni correction).

†Indices for correction of passage of proteins from peripheral blood in CSF according to the formula:

Protein index $=[\mathrm{CSF}$ protein] $/[$ serum protein $]$ 


\section{Discussion}

Many factors discussed as inducers of vasospasms in subarachnoidal haemorrhage (for example, erythrocyte or platelet derived substances) are absent in bacterial meningitis. This investigation of humoral factors possibly involved in pathogenesis of cerebrovascular complications in bacterial meningitis focused on leucocytes and inflammatory mediators. The results show significantly higher leucocyte counts and a significantly increased compartmentalised synthesis of IL- $1 \beta$ and IL- 6 in the CSF of patients with high CBFVs. Concentrations of keto-prostaglandin $\mathrm{F}_{1 \alpha}$-the stable metabolite of prostacyclin-but not of thromboxane $\mathrm{B}_{2}$ - the stable metabolite of thromboxane $\mathrm{A}_{2}$-were significantly increased in meningitis. A clear shift of the equilibrium between the antagonistic acting eicosanoids towards the vasoconstrictor thromboxane $A_{2}$ could not be demonstrated. Concentrations of endothelin-1 in CSF were highly variable, as were concentrations of the eicosanoids. Possible reasons may be a considerable variation in the degree of blood-brain barrier disruption, or a different extent of systemic inflammation and infection in these patients. Concentrations of endothelin tended to be increased, but not significantly, in patients with meningitis. Interestingly, four patients exhibited high endothelin concentrations in CSF but not in venous blood, suggesting intrathecal synthesis in some patients.

The cause of relatively high indices of eicosanoids and endothelin in normal controls is unclear. Concentrations in a similar range have been reported. ${ }^{18} 25$ Possible explanations may be a higher rate of proteolytic degradation in venous blood than in CSF, or an intrathecal synthesis even in the normal condition.

As in subarachnoid haemorrhage, in which the research for one single factor causing vasospasm has been disappointing, a multifactorial origin of vasospasms is most likely in meningitis. The increased compartmentalised synthesis of proinflammatory cytokines and raised leucocyte counts in patients with high CBFVs suggests a role of excessive host defence to bacterial outer cell membrane components in pathogenesis of vasospasms. The interleukins IL- $1 \beta$ and IL- 6 play a key part in inflammation and early immunoactivation, orchestrating a cascade of further proinflammatory and contrainflammatory immunomediators. ${ }^{1026}$ High concentrations of these immunomediators in CSF may exert vasoactive effects-for example, IL-1 $\beta$ (MW $17000 \mathrm{Da}$ ) or IL-6 (MW $26000 \mathrm{Da}$ ) could easily get access to the walls of contiguous basal arteries from their adventitial side-as even larger molecules (for example, horseradish peroxidase, MW $40000 \mathrm{Da}$ ) pass from the cysterna magna through the vessel wall to the basal membrane within minutes. ${ }^{27}$ This is possible because, by contrast with other arteries, the surface of the major cerebral arteries is not confined by collagen or fibroblasts, but is in direct contact with the CSF. ${ }^{27}$ At this location, proinflammatory cytokines could alter vessel tone either directly or indirectly-for example, by induction of synthesis of endothelin-1 by endothelial or other cells, as has recently been shown in vitro. ${ }^{2021}$ It is still controversial whether inflammatory exudate is harmful or helpful in infection. Vasoconstrictive properties of leucocytes and their products could also be, within certain limits, of benefit in acute inflammation - for example, in impairment of spreading of infectious agents or pluripotent immunomediators. Earlier studies showed that adjuncts to antibiotic treatment that reduce inflammation - for example, corticosteroids or treatments aimed to decrease the accumulation of leucocytes in CSF - have the potential to reduce mortality, ${ }^{28}$ although further research is necessary. ${ }^{29}$ Such strategies could be useful in prophylaxis and treatment of cerebrovascular complications of bacterial meningitis. Because IL-6 and other cytokines have recently been detected in the CSF of patients with subarachnoidal haemorrhage, ${ }^{30}$ investigation of immunomediators may also be an interesting approach in elucidation of the pathogenesis of vasospasms in subarachnoid haemorrhage.

In conclusion, the increase of key mediators of immunoactivation and of leucocyte counts in the CSF of patients with high CBFVs suggests a role of excessive host defence compartmentalised in the subarachnoidal space in pathogenesis of vasospasms in bacterial meningitis.

We acknowledge the excellent technical assistance of Ms Poltersdorf and Ms Kornmüller and the expert criticisms of Dr Berthold.

1 Pfister HW, Borasio GD, Dirnagl U, Bauer M, Einhäupl KM Cerebrovascular complications of bacterial meninKM. Cerebrovascular complications of bacte

2 Thomas VH, Hopkins IJ. Arteriographic demonstration of vascular lesions in the study of neurologic deficit in advanced Haemophilus influenzae meningitis. Dev Med Child Neurol 1972;14:783-7.

3 Igarashi M, Gilmartin RC, Gerald B, Wilburn F, Jabbour JT. Cerebral arteritis and bacterial meningitis. Arch Neurol 1984;41:531-5.

4 Yamashima $T$, Kashihara $K$, Ikeda K, Kubota $T$, Yamamoto S. Three phases of cerebral arteriopathy in meningitis: vasospasm and vasodilatation followed by organic stenosis. Neurosurgery $1985 ; 16: 546-53$.

5 Haring HP, Rötzer HK, Reindl H, Berek K, et al. Time course of cerebral blood flow velocity in central nervous system infections. Arch Neurol 1993;50:98-101.

6 McMenamin JB, Volpe JJ. Bacterial meningitis in infancy: effects on ICP and cerebral blood velocity. Neurology effects on ICP

7 Bode H, Harders A. Transient stenoses and occlusion of main cerebral arteries in children-diagnosis and control of therapy by transcranial

8 Aaslid R, Huber P, Nornes H. Evaluation of cerebrovascular spasm with transcranial Doppler ultrasound. $f$ Neurosurg 1984;60:37-41.

9 McAllister CK, O'Donoghue JM, Beaty HN. Experimental pneumococcal meningitis. II. Characterization and quantification of the inflammatory process. $\mathcal{F}$ lnfect Dis 1975 ; 132:355-60.

10 Akira S, Hirano T, Taga T, Kishimoto T. Biology of multifunctional cytokines: IL-6 and related molecules (IL-1 and TNF). FASEB $\mathcal{F}$ 1990;4:2860-7.

11 Fassbender $\mathrm{K}$, Parrger $\mathrm{H}$, Müller W, Zimmerli W. Interleukin-6 and acute phase protein concentrations in surgical intensive care unit patients: diagnostic signs in nosocomial infection. Crit Care Med 1993;21:1175-80.

12 Waage A, Halstensen A, Shalaby R, Brandtzaeg P, Kierulf P, Espevik T. Local production of tumor necrosis factor Espevik $T$. Local production of tumor necrosis factor
alpha, interleukin 1 , and interleukin 6 in meningococcal alpha, interleukin 1 , and interleukin 6 in meningococcal meningitis. Relation to the

13 Vane JR. Prostaglandins as mediators of inflammation. In: Samuelson B, Paoletti R, eds. Advances in prostaglandin and thromboxane research. New York: Raven Press, 1976 2:791-801.

14 Chan RC, Durity FA, Thompson GB, Nugent RA, Kendall $M$. The role of the prostacyclin-thromboxane system in cerebral vasospasm following induced sub- 
arachnoidal hemorrhage in the rabbit. $f$ Neurosurg 1984;61:1120-8.

15 De Caterina R, Sicari R, Giannessi D, et al. Macrophagespecific eicosanoid synthesis inhibition and lipocortininduction by glucocorticoids. F Appl Physiol 1993;75: 2368-75.

16 Ide $\mathrm{K}$, Yamakawa $\mathrm{K}$, Nakagomi $\mathrm{T}$, et al. The role of endothelin in the pathogenesis of vasospasm following subarachnoid hemorrhage. Neurol Res 1989;11:101-4.

17 Asano T, Ikegaki I, Suzuki Y, Sato S, Shibuya M. Endothelin and the production of cerebral vasospasm in Endothelin and the production of cerebral vasospasm
dogs. Biochem Biophys Res Commun 1989;159:1345-51.

18 Ehrenreich $\mathrm{H}$, Anderson RW, Fox $\mathrm{CH}$, et al. Endothelins, peptides with potent vasoactive properties, are produced by human macrophages. F Exp Med 1990;1 72;1741-8.

19 Morita T, Kuhihara H, Yoshizumi M, et al. Human polymorphonuclear leukocytes have dual effects on endothelin-1: the induction of endothelin-1 mRNA expression in vascular endothelial cells and modification of the endothelin-1 molecule. Heart Vessels 1993;8:1-6.

20 Endo T, Uchida Y, Matsumoto $\mathrm{H}$, et al. Regulation of endothelin-1 synthesis in cultured guinea pig airway epithelial cells by various cytokines. Biochem Biophys Res Commun 1992;186:1594-9.

21 Katabami T, Shimizu M, Okano K, et al. Intracellular signal transduction for interleukin-1 beta-induced endothelin production in human umbilical vein endothelial cells. production in human umbilical vein endothelia
Biochem Biophys Res Commun 1992;188:565-70.

22 Inoue A, Yanagisawa M, Takuwa Y, et al. The human preproendothelin-1 gene. $f$ Biol Chem 1989;264: 14954-9.
23 Hennerici M, Rautenberg W, Sitzer G, Schwartz A. Transcranial Doppler ultrasound for the assessment of intracranial arterial flow velocity. I: examination of technique and normal values. Surg Neurol 1987;27:439-48.

24 Röther J, Schwartz A, Wentz KU, Rautenberg W, Hennerici $M$. Middle cerebral artery stenosis: assessment by magnetic resonance angiography and transcranial Doppler ultrasound. Cerebrovasc Dis 1994;4:273-9.

25 GE, Bucholz RD, Yoon K-W, Knuepfer MM, Smith J KR. Cerebrospinal fluid endothelin-1 and endothelin-3 levels in normal and neurosurgical patients: a clinical levels in normal and neurosurgical patients: a clinical
study and literature review. Surg Neurol 1991;35:20-9.

26 Ristimaki A, Garfinkel S, Wessendorf J, Maciag T, Hla T. Induction of cyclooxygenase- 2 by interleukin-1 alpha. Evidence for post-transcriptional regulation. $\mathcal{F}$ Biol Chem 1994;269:11769-75

27 Zervas NT, Liszczak TM, Mayberg MR, Black PM Cerebrospinal fluid may nourish cerebral vessels through pathways in the adventitia that may be analogous to systemic vasa vasorum. I Neurosurg 1982;56:475-81.

28 Lebel MH, Freij BJ, Syrogiannopoulos GA, et al. Dexamethasone therapy for bacterial meningitis. Results of two double-blind, placebo-controlled trials. $N$ Engl $\mathcal{F}$ Med 1988:319:964-71.

29 Prasad K, Haines T. Dexamethasone treatment for acute bacterial meningitis: how strong is the evidence for routine use? $\mathcal{F}$ Neurol Neurosurg Psychiatry 1995;59:31-7.

30 Mathiesen T, Andersson B, Loftenius A, von Holst $H$. Increased interleukin-6 levels in cerebrospinal fluid following subarachnoidal hemorrhage. $\mathcal{F}$ Neurosurg 1993;78 562-7.

\section{Tinel's sign of formication}

Few signs have caused more controversy than the sign of Tinel.

Julius Tinel (1879-1952) was son of the professor of anatomy at Rouen. He worked with Dejerine, and became chef de clinique in 1911 and chief of the laboratory at Salpêtrière in 1913 . He was very active with his son Jacques in the French resistance movement in the second world war, and was imprisoned in Bordeaux at Fort de $\mathrm{Ha}$. His book Nerve Wounds records 639 patients with nerve injuries sustained in the first world war. He called his sign the sign of formication.

"The all important sign is formication. We find that sudden pressure or percussion of the nerve trunk, below the lesion, calls forth a tingling sensation in the cutaneous region of the nerve... It appears about the fourth or sixth week ... Then it gradually becomes more pronounced and it is possible to follow, week by week, in the course of the nerve, the progress of this provoked formication, pari passu with the advance of the axis cylinders. The formication sign is thus of supreme importance since it enables us to see whether the nerve is interrupted, or in the course of regeneration; whether a nerve suture has succeeded or failed, or whether regeneration is rapid and satisfactory, or reduced to a few significant fibres."!

Tinel's sign fell into disrepute when a positive sign was elicited in a patient in whom it was shown that there was an anatomical gap at the site of nerve injury. The salient feature is "peripheral reference" of the tingling sensation on percussion of the nerve that occurs in normal nerves; but in a pathological nerve it is more easily provoked and may persist longer. It may be used to localise the site of injury and suggests the presence of regeneration. Now widely used in nerve entrapment syndromes, it remains as a "soft sign". Second world war experience proved that a negative Tinel's sign is of no diagnostic value.

The translation of the two papers of Paul Hoffman, published in the same year that Tinel wrote his article (1915) has caused some authorities ${ }^{2}$ to refer to the Hoffman-Tinel sign.

J M S PEARCE 304 Beverley Road, Anlaby, Hull HU10 $7 B G$, UK
Heverley Road, Anlaby,

1 Tinel J. Les blessures des nerfs. Paris: Masson, 1916. 2 Buck-Grameko D, Lubahn JD. Hoffmann-Tinel sign. $f$ Hand Surg (Br) 1993;18:B/6. 